\title{
Nem privado nem estatal: a ideia de público como um sistema de comunicação
}

\section{Adilson Vaz Cabral Filho}

\section{Resumo}

Alguns países da América Latina estão assumindo um sistema de comunicação dividido em três partes, com base nos setores estatal, privado e público. A ideia de um Sistema de Comunicação Pública, diferente da estatal, é extremamente controversa na literatura atual sobre Políticas de Comunicação. Busca-se, neste trabalho, analisar o caso brasileiro, no qual não há nenhuma regulamentação específica para o que está mencionado na Constituição Brasileira como um "princípio de complementaridade mútua entre os sistemas privado, público e estatal", relacionando-o com a situação de outros países latinos. Este trabalho leva em consideração as recentes mudanças políticas e tecnológicas e o debate brasileiro recente sobre este tema. É baseado em pesquisa bibliográfica e documental, tendo em conta as experiências existentes, como rádios e televisões e outros meios de comunicação como telecentros e canais públicos de rádio e TV potencialmente disponíveis na transmissão digital.

\section{Palavras-Chave}

Sistema público de comunicação. Políticas de comunicação. Democratização da comunicação. Digitalização da comunicação. Comunicação comunitária

Adilson Vaz Cabral Filho I acabral@comunicacao.pro.br Doutor em Comunicação Social pela Universidade Metodista de São Paulo - UMESP. Professor do Curso de Comunicação Social e dos Programas de Pós-graduação em Políticas Sociais e de Mídia e Cotidiano da Universidade Federal Fluminense - UFF.

\section{Para compreender 0 debate sobre 0 Sistema Público de Comunicação}

Um dos debates mais atuais e urgentes no campo da Comunicação nos países da América Latina é o da compreensão e da efetivação de um sistema de comunicação de características não privadas nem estatais. Um sistema comprometido com a apropriação e a afirmação do processo regulatório por seus realizadores e demais ativistas; com a formulação e aplicação de políticas para garantir a viabilidade e a sustentabilidade das iniciativas em curso e de capacitação de distintos atores; e com 0 fomento de novas experiências relacionadas aos mais diferenciados grupos, organizações e movimentos nos mais distintos contextos. Em resumo, um sistema público de comunicação.

0 papel da comunicação vem sendo recentemente compreendido na afirmação das diferentes áreas sociais, tais como moradia, educação, saúde, segurança, na mesma medida em que novas formas de produção, transmissão, recepção e compartilhamento de conteúdos 
midiáticos vêm sendo apreendidos por ativistas, contribuindo para dinamizar os modos de fazer comunicação numa perspectiva contrahegemônica, mas também para pautar 0 debate sobre a regulamentação do setor numa escala mais ampla e incorporando novas questões, como a do financiamento público de caráter estatal.

A produção em Comunicação por parte de organizações da sociedade civil e produtores independentes de caráter público já era vislumbrada por autores como Brecht (apud ORTRIWANO, 1999, p. 2) -, para quem o rádio seria "[...] um fantástico sistema de canalização, se fosse capaz, não apenas de emitir, mas também de receber" - e Enzensberger (1979, p. 90) que afirmava, em relação às tecnologias de vídeo e filme que já se tornavam acessíveis à população na Alemanha, "[...] cabe perguntar por que tais meios de produção não aparecem maciçamente nos locais de trabalho, nas escolas".

A confecção do Relatório McBride, ainda em 1968, afirmou de modo sistêmico essa concepção numa perspectiva multilateral, quando já levava em conta que "[...] indivíduos e grupos podem (ou poderão proximamente) utilizar os seus meios de comunicação e recursos próprios, ao mesmo tempo que os dos meios de comunicação social" (UNESCO, 1983, p. 349). Desse modo, torna-se real a compreensão do papel da apropriação social das Tecnologias de Informação e Comunicação (TICs) na confecção de meios próprios com o efetivo barateamento das tecnologias de gravação e edição e a recente facilitação de acesso à veiculação das produções.

Na continuidade das experiências de comunicação popular que marcaram os anos 70 e 80 do século passado na América Latina rádios comunitárias ligadas a movimentos de trabalhadores e moradores, experiências de vídeo popular interligadas em associações nacionais e movimento latino-americano - e das iniciativas que redefiniram as políticas do setor em outras bases a partir dos anos 90 no Brasil - canais comunitários de TV à Cabo, a partir da Lei n. 8.977, de 1995, e rádios comunitárias legalizadas a partir da Lei n. 9.612, de 1998 -, os movimentos ligados ao setor vêm formulando estratégias para a implementação do Sistema Público de Comunicação, tal como formulado no artigo 223 da Constituição Federal, que remete à mútua complementaridade na forma do seguinte texto: "compete ao Poder Executivo outorgar e renovar concessão, permissão e autorização para o serviço de radiodifusão sonora e de sons e imagens, observado o princípio da complementaridade dos sistemas privado, público e estatal".

Em artigo publicado no Observatório de Imprensa, por ocasião do falecimento do Deputado Arthur da Távola, o professor Venício Lima (2008) revela a motivação da existência do Sistema Público de Comunicação no texto constitucional de 1988. Para o autor, 0 parlamentar acreditava que haveria lugar para um sistema "organizado por instituições da 
sociedade e que funcionasse independente do Estado e do capital".

Um texto posterior, de Mariana Martins ${ }^{1}$, cita 0 artigo de Venício Lima, contrapondo-0 aos posicionamentos dos professores Murilo César Ramos e Marcos Dantas, para quem a distinção entre estatal e público é uma confusão conceitual: "Não existe diferença entre 'estatal' e 'público'. 0 que é estatal é público, pois o Estado é, ou deve ser, público", de acordo com Marcos Dantas e "[...] a separação entre o público e o estatal transformou-se em uma armadilha normativa que acabou por escapar a todos os especialistas naquele momento", nos dizeres de Murilo César Ramos.

Venício Lima, por sua vez, ${ }^{2}$ retoma seu texto anterior, afirmando que 0 constituinte Artur da Távola já defendia "[...] a ideia de um (sistema) público que represente não apenas o Estado, mas o que houver de possivelmente organizado na chamada sociedade". Pensava não somente em iniciativas como a BBC britânica, mas outras, cujas concessões eram outorgadas diretamente às universidades, por exemplo.

0 debate mais recente sobre 0 tema, no entanto, tem suas origens durante a Cúpula Mundial pela Sociedade da Informação, realizada em dezembro de 2003, em Genebra, e em novembro de 2005, na Tunísia. As organizações da sociedade civil realizaram a Campanha CRIS - Sociedade da Informação pelo Direito à Comunicação, resultando na reivindicação de propostas voltadas para a afirmação da comunicação como um direito humano.

No Brasil, como parte dessa mobilização mundial, foi implementado o Capítulo CRIS Brasil, contando com o Sistema Público de Comunicação como um de seus eixos centrais de atuação, no marco do Programa de Governança Global, escrito, além do Brasil, por outros quatro capítulos participantes da Campanha CRIS: Colômbia, Filipinas, Itália e Quênia.

0 Sistema Público de Comunicação é reivindicado no âmbito das iniciativas que se expandem em todo o país, e que seriam de número muito maior caso não houvesse uma repressão tão incisiva pelo governo brasileiro, principalmente em relação às rádios comunitárias, mas também diante da falta de incentivos aos canais comunitários de TV a Cabo e de vontade política em torno dos futuros Canais da Cidadania no contexto da TV Digital, que nem sob a gestão própria das organizações da sociedade foram concebidos,

Publicado em 14/10/2008. Disponível em http://www.direitoacomunicacao.org.br/content.php? option=com_ content\&task=view\&id=4132. Acesso em 01/04/2009.

Publicado em 15/01/2009. Disponível em http://www.observatoriodaimprensa.com.br/news/view/ o_principio_da_ complementaridade. Acesso em 01/04/2009. 
no que se refere ao Decreto n. 5.820/2006, ${ }^{3}$ que os instituiu.

No contexto da Campanha CRIS, o Sistema Público de Comunicação foi motivo de uma campanha lançada a partir do "Seminário Cris Brasil: 0 direito à comunicação e o Sistema Público de Comunicação", em 2005. Se para Taís Ladeira, na época, representante da Associação Mundial de Rádios Comunitárias (AMARC) no Brasil e também coordenadora da Cris Brasil, cabia "[...] mostrar para a sociedade brasileira que há alternativas fora dos sistemas privados e estatais", João Brant, do Intervozes, declara que "[...] 0 sistema público de comunicação deve ter mecanismos que permitam à sociedade se apropriar, sem fins lucrativos, da mídia, estimulando a pluralidade e a diversidade dos meios e dos conteúdos" (MOYSES, 2005).

\section{A compreensão do Sistema Público de Comunicação no meio acadêmico}

0 recente debate no contexto acadêmico busca recompor o papel do Sistema Público de Comunicação sob a responsabilidade do Estado, para além do sistema estatal já expresso na Constituição Federal. Considera que cabe ao Estado a implementação de serviços públicos e de iniciativas de interesse público, pautadas pelo caráter público. Duas evidências para a visibilidade desse debate são a Empresa Brasileira de Comunicação, a EBC, que incorpora, sob o comando do Estado, aspectos determinantes do que poderia ser a efetivação Do Sistema Público de Comunicação no país, visto que responsável pela TV Brasil, chamada de "TV Pública" por governantes, pesquisadores e ativistas, além da configuração do campo público das experiências de TVs e de Rádios, com a participação de emissoras estatais (TV Câmara, TV Senado, dentre outras) e até mesmo privadas, como as de TVs de universidades particulares, vinculadas à Associação Brasileira de TVs Universitárias (ABTU).

Este posicionamento - que concebe 0 Estado como responsável, gestor e empreendedor do Sistema Público de Comunicação para além do próprio sistema estatal pelo qual é naturalmente responsável - é recente pelo que destoa da mobilização das últimas décadas de ativistas e militantes pela comunicação democrática como direito humano. Mas resgata uma concepção tradicional do caráter público do Estado, na realização de serviços públicos voltados para 0 interesse público, numa matriz ideológica que não considera a pertinência da legitimidade reivindicada pelos produtores de mídia que se situam no âmbito do Sistema Público de Comunicação. Dessa maneira sublima o papel da

Art. 13. A União poderá explorar o serviço de radiodifusão de sons e imagens em tecnologia digital, observadas as normas de operação compartilhada a serem fixadas pelo Ministério das Comunicações, dentre outros, para transmissão de: [...] IV - Canal de Cidadania: para transmissão de programações das comunidades locais, bem como para divulgação de atos, trabalhos, projetos, sessões e eventos dos poderes públicos federal, estadual e municipal. 
sociedade organizada autonomamente em função da supervalorização do Estado em sua capacidade de gerir processos.

Outra face de uma mesma subvaloração da capacidade gestora de organizações da sociedade está manifesta no Decreto $\mathrm{n}$. 5.820/2006 que instituiu a TV Digital no Brasil, ao enquadrar o Canal da Cidadania sob a guarda do Ministério das Comunicações, contra a qual se organizam manifestações recentes contra a TV Digital são organizadas para a incorporação da programação dos canais comunitários nos canais da TV Digital e da mobilização preparatória para a I Conferência Nacional de Comunicação (I Confecom), na expectativa de obter consensos possíveis em relação ao reconhecimento dessas iniciativas.

Realizada de 14 a 17 de dezembro de 2009, a I Confecom aprovou, dentre as 672 propostas definidas na ocasião, uma que explicita essa concepção de Sistema Público de Comunicação:

Regulamentar 0 artigo 223 da Constituição Federal, definido os sistemas público, privado e estatal. 0 primeiro deve ser entendido como aquele integrado por organizações de caráter público geridas de maneira participativa a partir da possibilidade de acesso universal do/a cidadão/s, suas estruturas dirigentes e submetida a controle social (BRASIL, 2010).
Comunicação, necessitam empreender melhor sua capacidade de ocupação dos espaços disponíveis, além de conceber e implementar uma proposta contra-hegemônica que incida claramente na política de sua gestão e programação e na estética de suas produções e linguagens, de sustentação e de visibilidade de suas atividades.

0 governo brasileiro também usa de argumentos de desqualificação nessa linha, alegando que as iniciativas de comunicação da sociedade deveriam ter conteúdos de qualidade para mostrar e poder reivindicar faixas de frequência. Tal argumentação equivale à desconstrução que o Mercado costuma afirmar em seus posicionamentos, quando na verdade o próprio governo deveria ser o primeiro ator a impulsionar e a estar ao lado dessa apropriação por parte das iniciativas empreendidas pela sociedade organizada. Ainda mais que, historicamente, 0 papel de governos anteriores que não causam nostalgia à população brasileira foi exatamente o de fomentar a qualidade de conglomerados nacionais a partir da liberação de subsídios estrangeiros, que superaram suas limitações estéticas e técnicas, estabelecendo padrões de qualidade que levaram a sociedade a legitimá-los, praticamente revertendo a afirmação de poder em relação a governantes e parlamentares.

Cabe, diante desse cenário, a elaboração de outro projeto estratégico nacional pela criação de um sistema público de comunicação como 
mídia de todos, compreendendo que somente a sociedade organizada é quem pode concebê-lo e reivindicá-lo, posto que o conceito está em aberto, no que tange a Constituição Federal, e não regulamentado, na ausência de um processo regulatório direcionado ao setor.

\section{A compreensão do Sistema Público de Comunicação entre a sociedade organizada}

Distinto do estatal e do privado, mas em mútua complementaridade com eles, impulsionado pelo barateamento das tecnologias de produção e de edição, além do acesso facilitado à veiculação e ao compartilhamento de conteúdos, o Sistema Público de Comunicação emerge da afirmação de experiências de diferentes contextos ao longo das cinco últimas décadas de articulação entre grupos de assessoria ou das próprias comunidades nas quais atuam, que realizam iniciativas de comunicação compreendidas como popular, comunitária, independente, alternativa, cidadã além de outras denominações mais recentes como mídia radical ou tática.

Tal como as emissoras relacionadas ao sistema estatal, se constitui por iniciativas que também promovem o serviço público, imbuídos do caráter e do interesse público no âmbito de sua programação e, especificamente, de seus programas e conteúdos. Destina-se, portanto, ao compromisso com assuntos e abordagens relacionados ao conjunto da sociedade e, especificamente, ao público relacionado à sua área de atuação. Também a gestão precisa assimilar princípios públicos de diversidade e pluralidade na sua concepção e formação, afirmando espaços para o fomento de autonomia, empoderamento, protagonismo social, tendo como referência a concepção dos Pontos de Cultura no Projeto Cultura Viva, do Ministério da Cultura - MinC.

Por um lado, parte da necessidade de incorporar espaços já disponibilizados, como canais comunitários de TV a Cabo e fomentar o debate e a participação política em torno da transição para a digitalização da TV e do Rádio. Por outro, cabe também buscar construir, mas também reivindicar políticas de fortalecimento de suas iniciativas, como sustentabilidade, visibilidade e capacitação, nas quais o Estado possa compreender um papel determinante.

Fortalecer iniciativas e experiências nesse sentido é fundamental. Compreender a necessidade de apropriação do processo regulatório é empreender uma dimensão política que expande limites de atuação local, mas tece conexões nas esferas regional, nacional e mesmo internacional, dado que as redes encontram-se em construção desde os anos 90 do século passado.

Ao mesmo tempo, no que diz respeito à sociedade não engajada em iniciativas de grupo, coletivas, mas capaz de compreender a importância dos meios, produtos e processos comunicacionais, 
cabe identificar diferentes disposiç̧ões para apropriação das TICs e realização de produtos e processos comuns de diálogo e construção conjunta de políticas a serem formuladas nos mais diferentes espaços (conselhos municipais e estaduais, leis de incentivo a iniciativas de comunicação etc).

Experiência nessa concepção foi realizada em junho de 2008, na cidade do Rio de Janeiro, no I Fórum de Mídia Livre, reunindo por volta de 600 pessoas entre ativistas de mídia, integrantes de movimentos sociais, pesquisadores, professores e demais interessados, que debateram e estabeleceram demandas para efetivar a comunicação democrática como direito humano no país, compreendendo não só a reconfiguração atual do sistema de comunicação no país, mas a efetivação de uma mídia livre e democrática a partir das múltiplas experiências que compõem o cenário daqueles que se identificam em torno da concepção de Mídia Livre. Experiência refeita em dimensão mundial durante 0 Fórum Social Mundial (FSM) de 2009, realizado na cidade de Belém do Pará, contando com participantes de outros países, no qual foi possível estabelecer uma crítica mais ampla ao papel da Comunicação no cenário mundial, compreendida num momento em que "novas formas de resistência e contra-discursos surgem e se disseminam" diante da concentração das grandes corporações de mídia, explicitando 0 papel desses grupos como suporte do discurso hegemônico, revitalizando o debate promovido nos tempos da mobilização em torno da Cúpula Mundial pela Sociedade da Informação e da Campanha CRIS.

Outro aspecto importante a se considerar é 0 de que a afirmação das demandas sociais relacionadas à área da Comunicação não é suficiente no âmbito restrito dos movimentos pela democratização da comunicação, carecendo de uma melhor participação de outros setores da sociedade, manifestados através de suas associações e movimentos mais representativos, mas também da incorporação das temáticas relacionadas à comunicação na compreensão de suas agendas mais específicas.

\section{Da comunicação comunitária ao Sistema Público de Comunicação}

Para deixar clara a proposta em torno desse artigo, não se trata de igualar sinais entre iniciativas de comunicação comunitária tal qual atualmente implementadas, mas de buscar critérios que efetivem a compreensão do que se pode conceber como serviço de caráter e voltado para 0 interesse público no que diz respeito à Comunicaçãa.

A comunicação comunitária é própria da comunidade, representada por uma dimensão territorial que tece seus limites e fronteiras. É assim com os casos brasileiros da Lei de Radiodifusão Comunitária (1998), e também com a Lei de TV a Cabo (1995). Se a primeira limita ao raio de 25 watts de potência e $1 \mathrm{~km}$ de 
distância do sinal, a segunda limita à cidade na qual existe outorga para TV a Cabo. Essas são as compreensões de comunidade e atividade comunitária estabelecidas no âmbito do Legislativo e exercidas pelos grupos interessados para implementar suas emissoras e programas. Ou ainda, este é o território em torno do qual as experiências comunitárias se assentam no país.

Embora comunidade sempre estivesse relacionada a uma imagem de território e/ou de afinidade de um determinado grupo, o sentimento de pertença consiste num desafio cada vez maior entre os participantes de um dado local. A despeito da abstração conceitual contida na Lei da TV a Cabo, equivalendo comunidade ao contexto de cidades amplas como Rio de Janeiro, São Paulo, Belo Horizonte ou Porto Alegre, o movimento de rádios comunitárias, a partir de suas rádios associadas, se ressente de um engajamento mais contínuo dos moradores nas suas localidades de atuação, até pela repressão policial que inibe uma melhor participação das pessoas, o que limita a efetivação de um espírito comunitário ou mesmo de coletividade em torno dos projetos.

0 sentido do engajamento, fruto da pertença, é justamente a consciência da condição de exploração, mesmo que essa se dê meramente no campo simbólico da necessidade de se expressar a partir da realização de seus próprios programas e processos. Embora esse processo se dê com muita clareza a partir da afirmação de uma condição de classe, também a imposição da força, nos mais variados contextos - gênero, etnia, infância/adolescência, combate às drogas e à pedofilia, dentre outras temáticas -, constroem um cenário mais amplo, complexo e dinâmico do que o movido simplesmente pelas relações entre capital e trabalho.

Em contrapartida, a necessidade de afirmação da sociedade através dessas iniciativas de caráter comunitário se dá através da contestação, da valorização da autoestima; da afirmação da cidadania e do resgate cultural; da mobilização no caminho contrário da midiatização, cujo simbolismo impregna a sociedade de expressões, personagens e mesmo de toda uma agenda que a torna refém legitimadora ao invés de sujeitos plenos dos processos políticos e culturais que empreendem; da emancipação e da autonomia no contraponto da mercantilização das iniciativas, que recolocam a disposição coletiva na perspectiva da exploração de uns contra outros e da formação de hierarquias nas comunidades; do desenvolvimento de novos modelos bottom-up, nos moldes das recém-concebidas mídia radical, mídia tática etc.

Num contexto mais geral, o embate entre a consciência de superar exploração e opressão por parte de grupos e organizações encontra respaldo e amplitude nos chamados novos movimentos sociais e no movimento alterglobalização, que encontra no Fórum Social Mundial um de seus territórios mais expressivos, dada a capacidade 
de mobilização de pessoas, suas agendas e formas de expressão e protesto de suas ideias em detrimento da apreensão da vitalidade das populações na concepção do chamado Terceiro Setor, pensado desde sua origem conceitual na mesma estrutura com outros dois setores, o Estado e o Mercado, no âmbito da mercantilização da atividade social.

Ao contrário do Sistema Público de Comunicação, concebido como outro distinto do estatal e do privado, no marco do sistema de comunicação no País, o Terceiro Setor não assume especificidade pública - de serviço, interesse e caráter - dada a inexistência de critérios determinantes de sua gestão e sustentabilidade. A sociedade mantém 0 Estado e pode almejá-lo, ao participar de partidos e campanhas políticas voltadas para cargos na sua gestão e estrutura. Da mesma forma, mantém o Mercado, nos moldes de dos empreendimentos privados que implementa.

Distintas dessas formas de organização, as iniciativas em torno do sistema público necessitam de critérios que os tornem de evidente interesse e acesso para a coletividade, sem distinção, reconhecendo suas particularidades em função da autonomia que afirmam e sustentam. Assim sendo, cabe distingui-lo de outras abordagens que tentam defini-lo como privado não-comercial ou público não-estatal: se, em relação ao primeiro termo, o interesse e 0 caráter são suficientes para estabelecer a devida distinção, cabe, diante da segunda abordagem, afirmar a capacidade da sociedade organizada em grupos sem fins lucrativos, distinta do Estado e seu sistema estatal de comunicação, de gerir um sistema de comunicação do povo, do público por sua própria natureza.

No campo da Comunicação os critérios para identificar a pertinência ao Sistema Público de Comunicação se dão em torno de componentes como a gestão, a programação das emissoras, a produção dos programas, as linguagens utilizadas, a articulação com movimentos e organizações sociais. A responsabilidade de tais iniciativas fica por conta de organizações da sociedade civil, compreendidas no contexto do sistema de comunicação que não compreende iniciativas estatais ou privadas, mas promove interlocuções com elas. Tais organizações podem ser definidas como pessoas, grupos e organizações sociais excluídos, vitimados ou restritos da participação em processos de produção de comunicação de amplo alcance, especialmente relacionados ao espectro eletromagnético (rádio e TV). No caso, pessoas e grupos relacionados a essa compreensão participam apenas como produtores das emissoras, dada a necessidade de serem geridas por organizações sociais juridicamente constituídas, mesmo que na forma das conhecidas "associações de amigos".

\section{Construindo o marco regulatório}

O desafio da construção da I Confecom, realizada de 14 a 17 de dezembro de 2009, a partir de eventos preparatórios municipais e estaduais, 
confronta a sociedade com a necessidade de promover debates e apresentar propostas aos temas relacionados à digitalização das comunicações e à convergência tecnológica. 0 cenário de construção da I Conferência compreendeu um Executivo permissivo em relação à repressão policial e políticas às rádios comunitárias. Destituído de vontade política em empreender um padrão brasileiro de TV Digital após ter investido uma verba considerável nas universidades brasileiras, se mostrou conivente com um Legislativo formado por concessionários de Rádio e TV a despeito da Constituição Federal, além de estabelecer a condição de que a sociedade fizesse a interlocução com 0 mercado para garantir condições de convocação da I Confecom por parte do governo.

Os grupos e organizações mais diretamente relacionados com o setor de Comunicação no País necessitam aprimorar sua capacidade de agregar setores da sociedade que também são vitimizados pela concentração dos grupos de mídia no País.

0 recente episódio da adoção do padrão de modulação da TV Digital Terrestre no País é mais um exemplo disso, na qual o distanciamento e a incapacidade de perceber a centralidade da Comunicação em relação ao conjunto de suas questões específicas enfraquecem a capacidade de conquistar adesões por uma transformação.

As diferenças de concepção demarcadas pelo tamanho do distanciamento em relação ao Governo Lula estão proporcionando um refreamento de ações políticas e sociais relevantes e de resultados concretos. Exemplo disso pode ser considerada a entrada dos canais comunitários de TV a Cabo nos canais públicos da TV Digital, em virtude da maior ou menor vinculação de componentes do movimento pela democratização da comunicação com a condução e a própria implementação direta das políticas no âmbito governamental.

Causou até mesmo estranheza a falta de disposição das organizações da sociedade civil em relação à continuidade da mobilização em torno da Ação Direta de Inconstitucionalidade n. 3944 impetrada pelo PSOL, na tentativa de apontar irregularidades no Decreto $n$. 5.820/2006, que adotou o padrão japonês de modulação em implementação no Brasil. Essa opção nunca deixou de existir, e se colocou sempre como uma alternativa para as organizações da sociedade civil empenhadas na democratização da digitalização das comunicações, até o momento de seu parecer definitivo por parte do Supremo Tribunal Federal, sem o devido engajamento por parte das organizações sociais.

0 governo - que já chegou a destinar verba na Lei de Diretrizes Orçamentárias relacionada à criação do Grupo de Trabalho Interministerial para implementar a Lei Geral de Comunicação - dá continuidade a sua política de oferecer expectativas a uma militância que não perde esperança em sua capacidade de empreender 
uma política democrática para as comunicações no País, apesar de todos os indícios contrários. Exceção feita às iniciativas relacionadas ao Ministério da Cultura, no marco do Programa Cultura Viva e dos Pontos de Cultura e de Mídia Livre, dentre outras realizações, embora caiba salientar que dentro de um orçamento ínfimo que cabe à pasta a cada orçamento aprovado para 0 Governo Federal.

\section{Construindo concepções de autonomia}

0 barateamento dos equipamentos de produção e edição ainda no início dos anos 1980, proporcionou o começo da disseminação do vídeo popular entre os movimentos populares tradicionais, incentivando o surgimento da Associação Brasileira de Vídeo Popular (ABVP), relatado no livro A imagem nas mãos, de Luiz Fernando Santoro (1989). Posteriormente, ainda em torno da ABVP, surgiram diversos projetos de TVs comunitárias e de rua, geralmente por meio de Organizações Não-Governamentais (ONGs) de assessoria a grupos e movimentos populares. A diminuição de investimentos nesses projetos, provocada pela reorientação de interesses de agências de cooperação e de dirigentes de 0NGs locais, além das demandas impostas pela ABVP que passou a gerar projetos de iniciativa própria, mobilizando tempo e disposição de seus associados -, levaram à desmobilização dos associados e ao fim da entidade.
Ao mesmo tempo, os canais comunitários de TV a cabo, surgidos a partir da segunda metade da década de 1990, passam a ser mais acionados para veicular produções de vídeo, agora já contando com atores diversificados, mas não necessariamente ligados a movimentos sociais tradicionais. Atualmente diversas atividades de apropriação das TICs no âmbito local ou comunitário são acionadas ou viabilizadas mediante iniciativas de ONGs, de empresas ou mesmo do Governo - como é o caso das diversas redes de telecentros patrocinadas, em todo o País, ou dos já citados Pontos de Cultura desenvolvidos por iniciativa do MinC desde o início da gestão do ex-Ministro Gilberto Gil.

Muitas dessas iniciativas mais diretamente ligadas às comunidades de baixa renda estão promovendo uma interessante reviravolta no setor, já que assimilam a lógica, a prática e 0 conhecimento das ONGs empreendedoras de projetos de âmbito local. Geralmente inseridas nas próprias comunidades nas quais atuam e contando com moradores das próprias comunidades nos espaços de direção e gestão das atividades, tais iniciativas eliminam a existência de intermediários no apoio a projetos e fomentam a sustentabilidade de seus próprios projetos, conseguindo até mesmo interlocução direta com a mídia corporativa para ampliar sua visibilidade.

Tal como os intelectuais orgânicos concebidos na obra de Antônio Gramsci ${ }^{4}$, esses atores 
proporcionam a entrada em cena de um novo ator, o marqueteiro orgânico, numa espécie de versão 2.0 do Terceiro Setor, na medida da atuação em rede de iniciativas comuns por parte desses projetos comunitários que buscam sua viabilidade de modo efetivamente autônomo, mas ainda dentro da lógica do mercado do Terceiro Setor.

A produção de vídeo por alguns grupos populares - como a Central Única das Favelas, CUFA ou 0 Nós do Cinema - no início dos anos 1990/2000 é marcadamente definida por tal dinâmica, na qual o morador comunitário usa e é usado pela mídia corporativa, mas em momento algum a enfrenta ou desconstrói. Por isso a assimilação dessas novas TICs, comum aos projetos apoiados diretamente junto aos moradores das comunidades beneficiadas, não resulta numa contraposição ou mesmo questionamento à mídia tradicional.

Não só espaços já disponíveis, como os Canais Comunitários de TV a Cabo, não são aproveitados, como não há disposição desses atores em participar dos debates sobre a democratização do processo regulatório. Apesar disso, tais experiências é que vêm proporcionando a produção dos mais diferentes conteúdos, em histórias e acontecimentos, sobre as periferias do Brasil, em especial das cidades urbanas. Se, por um lado, a mídia corporativa possibilita a construção de uma visibilidade que os legitima junto a empresas estatais, por outro ainda persiste a mesma lógica de concentração e consequente dominação proporcionada pela comunicação no País.

As TVs comunitárias dos anos 1980 eram motivadas por um projeto maior do que as comunidades nas quais atuavam - TV Viva, em Recife; TV Maxambomba, em Nova Iguaçu; TV Sala de Espera, em Belo Horizonte; BEM TV, em Niterói, dentre outras -, relacionado à apropriação social das TICs, mas também à importância da democratização da comunicação para a sociedade que demandava democracia. Já as iniciativas atuais revelam imagens e cenas de uma realidade que não aparece na mídia corporativa e somente através de atores como os que implementam tais projetos é que são trazidos ao conhecimento da sociedade em geral esses novos olhares, tendo como diferencial 0 estímulo ao desenvolvimento de novas carreiras na realização audiovisual.

Se tanto iniciativas de comunicação comunitária quanto novas experiências relacionadas aos produtores de mídia dos anos 1990 e início do novo século consistem em segmentos do Sistema Público de Comunicação, eles próprios necessitam se engajar na mobilização para 0 estabelecimento de critérios e procedimentos transparentes e aplicáveis para a melhor compreensão e identificação deste sistema.

Um de seus grandes impasses e desafios é 0 da apropriação dos processos de digitalização das comunicações na expressão da autonomia 
popular visando a configuração de suas

iniciativas. A relação com a sociedade em geral

- que não produz efetivamente conteúdos que garantam e sustentem a programação - mas é potencialmente participante a partir dos mais diversos mecanismos de interatividade, precisa ser estabelecida na formulação de suas bandeiras de luta e perspectivas de adoção de políticas públicas, compreendendo o papel do Estado como fomentador do sistema público, na condição não só de regulador e fiscal, mas dando suporte financeiro e capacitação, cabendo à sociedade a reivindicação da efetividade de tal condição.

\section{Ecos da América Latina}

Diversas iniciativas estão em curso na América Latina, evidenciando a amplitude do debate e a compreensão da existência de um sistema público não estatal e não privado, com o qual o Estado assume compromisso em viabilizar.

\section{Na Argentina, a presidente Cristina Kirchner} está aprovando um Projeto de Lei de Serviços de Comunicação Audiovisual, que compreende uma porcentagem significativa de concessões para organizações privadas sem fins de lucro, em caráter equitativo com os setores estatal e privado (ARGENTINA, 2009). No Uruguai, a nova Lei de Radiodifusão Comunitária (URUGUAY, 2007) prevê um terço do espectro destinado a emissoras do setor comunitário. Por sua vez, a Venezuela consolida uma estrutura em rede de experiências como a Vive TV e a Rede Catia, mais vinculadas ao Governo Chávez, bem como a Asociación Nacional de Medios Comunitários, Livres y Alternativos (ANMCLA), que reivindica a democratização dos meios de comunicação mediante a organização e articulação de um Sistema Público de Comunicação nas mãos das comunidades, tal como publicado em seu site oficial. ${ }^{5}$

Equador e Bolívia esboçam também a realização de estruturas semelhantes, baseadas no documento da Comissão Interamericana de Direitos Humanos intitulado Declaração de

\section{Princípios sobre Liberdade de expressão,}

no qual se lê que "a concessão de frequências de rádio e televisão deve considerar critérios democráticos que garantam a igualdade de oportunidades de acesso para todos os indivíduos". Os três últimos países citados configuram, para Dênis de Moraes (2009 p. 196), o bloco "mais ativo na proposição de novas legislações de radiodifusão, na reorientação de investimentos estatais e no fomento à difusão não mercantilizada" da América Latina.

Tal como no Brasil, a maioria desses países também conta com movimentos e organizações mais diretamente vinculadas aos governos, sobre os quais recaem críticas de favorecimento em processos de concessão, acesso a verbas estatais etc, acionados por uma mídia que historicamente 
teve acesso aos meios tecnológicos de grande alcance para disseminar seus credos e medos.

A apropriação dos meios de produção no contexto mais específico dos meios de comunicação visa promover a supressão da contraposição entre produtores e consumidores. Repensar 0 pensamento crítico nessa perspectiva necessita empreender 0 fomento à conscientização e à mobilização para 0 ativismo, não somente midiático, mas tendo, na compreensão da comunicação, a clareza de sua fundamental contribuição na sociedade contemporânea.

Compreende-se, portanto, nesse contexto, a contribuição da construção de políticas públicas de comunicação a partir de processos comunicacionais emergentes, dos quais fazem parte as iniciativas de comunicação comunitária. Apesar disso, para efeito da configuração do Sistema Público de Comunicação, uma série de indicadores necessitam ainda ser formulados e afirmados coletivamente como referência e orientação para iniciativas distintas que almejem atuar nessa perspectiva.

Trata-se de um longo caminho de compreensão dessas políticas e seus benefícios, mas 0 engajamento conjunto, a partir de experiências empreendidas desde 0 início dessa década, através de eventos e mobilizações em torno de causas comuns, permitem persistir na crença de que outra comunicação é possível e desejável para o Brasil, da qual faça parte um efetivo Sistema Público de
Comunicação, de iniciativas oriundas da sociedade e tendo o Estado como um de seus fomentadores.

\section{Referências}

ARGENTINA. Ley 26.522, de 10 de 0ctubre de 2009.

Regúlanse los Servicios de Comunicación Audiovisual en todo el ámbito territorial de la República Argentina. Disponível em: < http://www.comfer.gov.ar/web/ley26522. pdf> . Acesso em: 20 mar.2010.

BASES de um programa para a democratização da Comunicação no Brasil. 1994. Disponível em: < http:// www.fndc.org.br/doc_historico/data/programa.doc $>$. Acesso em: 13 dez. 2004.

BRASIL. Constituição da República Federativa do Brasil. Publicada em 19/04/2012. Disponível em http://www.planalto.gov.br/ccivil_03/Constituicao/ Constitui\%C3\%A7 ao.htm. Acesso em 19/04/2012.

BRASIL. Ministério das Comunicações. Caderno da $\mathbf{1}^{\mathrm{a}}$ Conferência Nacional de Comunicação. Brasília: Secretaria de Comunicação Social da Presidência da República, 2010. Disponível em < http://pfdc.pgr.mpf. gov.br/atuacao-e-conteudos-de-apoio/publicacoes/ comunicacao/caderno_1_confecom > . Acesso em: 20 mar.2010.

BRASIL. Ministério das Comunicações. Lei de Radiodifusão Comunitária. 1998. Disponível em http:// www.planalto.gov.br/ccivil_03/leis/L9612.htm. Acesso em: 19 abr. 2012.

BRASIL. Ministério das Comunicações. Lei de TV a Cabo. 1995. Disponível em http:// www.planalto.gov. br/ccivil_03/leis/L8977.htm. Acesso em: 19 abr. 2012.

CABRAL, Adilson. A agenda política da comunicação: construindo pontes entre organizações sociais e acadêmicas. Disponível em http://www.comunicacao. pro.br/uff/ adilsoncabral_agendapolitica_ALAIC2006. 
doc. Acesso em 11/09/2007.

ENZENSBERGER, Hans Magnus. Elementos para uma teoria dos meios de comunicação. Rio de Janeiro: Tempo Brasileiro, 1979.

GOHN, Maria da Glória. (Org.). Movimentos Sociais no início do século XXI. Antigos e novos atores sociais. Petrópolis, RJ: Vozes, 2003.

LIMA, Venício A. de. Mídia: teoria e política. São Paulo: Perseu Abramo, 2001.

. Artur da Távola (1936-2008): um lutador pela comunicação democrática. Observatório da Imprensa, São Paulo, n. 485, 2008. Disponível em: < http://www.observatoriodaimprensa.com.br/artigos. asp?cod=485MEM002 > . Acesso em: 18 abr. 2012. MORAES, Dênis de (Org.). A batalha da mídia. Rio de Janeiro: Pão e Rosas, 2009.

MOYSES, Diogo. 2005: ano de enfrentamento no campo da comunicação. 2005. Disponível em: < http:// www.movimientos.org/foro_comunicacion/show_text. php3?key=5035> . Acesso em: 01 abr. 2009.

ORTRIWANO, Gisela Swetlana. Rádio: interatividade entre rosas e espinhos. Disponível em: http:// www.bocc.ubi.pt/pag/ortriwano-gisela-radiointeractividadade. html. Acesso em: 19/04/2012.

PAIVA, Raquel (Org.). 0 retorno da comunidade: os novos caminhos do social. Rio de Janeiro: Mauad, 2007.

PERUZZO, Cicilia M. Krohling. Comunicação nos movimentos populares. Petrópolis, RJ: Vozes, 1998.

UNESCO. Um mundo e muitas vozes: comunicação e informação na nossa época. Comissão internacional para 0 estudo dos problemas de comunicação. Rio de Janeiro: FGV, 1983.

\section{URUGUAY. Ley n. 18.232, Servicio Radiodifusión}

Comunitaria, de 22 de diciembre de 2007. Disponível em <http://200.40.229.134/leyes/AccesoTextoLey. asp?Ley=18232 \&Anchor $=>$. Acesso em: 20 mar. 2010. 


\begin{tabular}{|c|c|}
\hline $\begin{array}{l}\text { Neither private nor state: } \\
\text { the idea of public as a } \\
\text { communication system }\end{array}$ & $\begin{array}{l}\text { Ni privado ni estatal: la idea de } \\
\text { público como un sistema de } \\
\text { comunicación }\end{array}$ \\
\hline $\begin{array}{l}\text { Abstract } \\
\text { Some countries of Latin America are assuming a } \\
\text { communication system divided into three parts, on } \\
\text { the basis of state, private and public sector. The } \\
\text { idea of a public communication system, other than } \\
\text { the State, is extremely controversial in the current } \\
\text { literature on communication policies. The proposal } \\
\text { of this work is to analyze the case of Brazil, in which } \\
\text { there are no specific rules for what it is mentioned } \\
\text { in the Brazilian Constitution as a "principle of } \\
\text { mutual complementarity among public, private and } \\
\text { state systems", relating it to the situation of other } \\
\text { Latin countries. This paper takes into account } \\
\text { recent technological and political changes and the } \\
\text { brazilian recent debate on this topic. It is based on } \\
\text { documentary and bibliographic research, taking into } \\
\text { account the existing experiences, such as radios and } \\
\text { televisions and other communication media such } \\
\text { as telecentres and public channels TV and radio } \\
\text { potentially available digital transmission. } \\
\text { Keywords } \\
\text { Public communication system. Communication } \\
\text { policies. Democratization of communication. } \\
\text { Digitization of communication. } \\
\text { Community communication. }\end{array}$ & $\begin{array}{l}\text { Resumen } \\
\text { Algunos países de América Latina están tomando } \\
\text { un sistema de comunicación que se divide en tres } \\
\text { partes, estatal, privada y pública. La idea de un } \\
\text { sistema de comunicación pública, distinto del } \\
\text { Estado es sumamente controvertida en la literatura } \\
\text { actual sobre las políticas de comunicación. Lo que } \\
\text { se busca, en este trabajo, es analizar el caso de } \\
\text { Brasil, en el que no existen específicas reglas para lo } \\
\text { que se menciona en la Constitución como "principio } \\
\text { de complementariedad mutua entre los sistemas } \\
\text { público, privado y estatal" relativos a la situación de } \\
\text { otros países latinoamericanos. Este trabajo toma en } \\
\text { cuenta los últimos cambios tecnológicos y políticos } \\
\text { y el reciente debate brasileño sobre este tema. Se } \\
\text { basa en la investigación bibliográfica y documental, } \\
\text { teniendo en cuenta las experiencias existentes, } \\
\text { tales como televisores y radios y otros medios de } \\
\text { comunicación como telecentros y canales públicos } \\
\text { de TV y radio potencialmente disponibles en la } \\
\text { transmisión digital. } \\
\text { Palabras clave } \\
\text { Sistema de comunicación pública. Políticas de } \\
\text { comunicación. Democratización de la comunicación. } \\
\text { Digitalización de la comunicación. Comunicación de } \\
\text { la comunidad. }\end{array}$ \\
\hline
\end{tabular}




\section{Expediente}

A revista E-Compós é a publicação científica em formato eletrônico da Associação Nacional dos Programas de Pós-Graduação em Comunicação (Compós). Lançada em 2004, tem como principal finalidade difundir a produção acadêmica de pesquisadores da área de Comunicação, inseridos em instituições do Brasil e do exterior.
E-COMPÓS I www.e-compos.org.br I E-ISSN 1808-2599

Revista da Associação Nacional dos Programas

de Pós-Graduação em Comunicação.

Brasília, v.15, n.1, jan./abr. 2012.

A identificação das edições, a partir de 2008

passa a ser volume anual com três números.

\section{CONSELHO EDITORIAL}

Afonso Albuquerque, Universidade Federal Fluminense, Brasil Alberto Carlos Augusto Klein, Universidade Estadual de Londrina, Brasil Álvaro Larangeira, Universidade Tuiuti do Paraná, Brasil Ana Carolina Damboriarena Escosteguy, Pontifícia Universidade Católica do Rio Grande do Sul, Brasil

Ana Gruszynski, Universidade Federal do Rio Grande do Sul, Brasil Ana Silvia Lopes Davi Médola, Universidade Estadual Paulista, Brasil André Luiz Martins Lemos, Universidade Federal da Bahia, Brasil Ângela Freire Prysthon, Universidade Federal de Pernambuco, Brasil Angela Cristina Salgueiro Marques, Faculdade Cásper Líbero (São Paulo), Brasil Antônio Fausto Neto, Universidade do Vale do Rio dos Sinos, Brasil Antonio Carlos Hohlfeldt, Pontifícia Universidade Católica do Rio Grande do Sul, Brasil Antonio Roberto Chiachiri Filho, Faculdade Cásper Líbero, Brasil Arthur Autran Franco de Sá Neto, Universidade Federal de São Carlos, Brasil Benjamim Picado, Universidade Federal Fluminense, Brasil César Geraldo Guimarães, Universidade Federal de Minas Gerais, Brasil Cristiane Freitas Gutfreind, Pontifícia Universidade Católica do Rio Grande do Sul, Brasil Denilson Lopes, Universidade Federal do Rio de Janeiro, Brasil Eduardo Peñuela Cañizal, Universidade Paulista, Brasil Eduardo Vicente, Universidade de São Paulo, Brasil Eneus Trindade, Universidade de São Paulo, Brasil Erick Felinto de Oliveira, Universidade do Estado do Rio de Janeiro, Brasil Florence Dravet, Universidade Católica de Brasilia, Brasil Gelson Santana, Universidade Anhembi/Morumbi, Brasil Gislene da Silva, Universidade Federal de Santa Catarina, Brasil Guillermo Orozco Gómez, Universidad de Guadalajara Gustavo Daudt Fischer, Universidade do Vale do Rio dos Sinos, Brasil Hector Ospina, Universidad de Manizales, Colômbia Herom Vargas, Universidade Municipal de São Caetano do Sul, Brasil leda Tucherman, Universidade Federal do Rio de Janeiro, Brasil Inês Vitorino, Universidade Federal do Ceará, Brasil Jnice Caiafa, Universidade Federal do Rio de Janeiro, Brasil Jay David Bolter, Georgia Institute of Technology Jeder Silveira Janotti Junior, Universidade Federal de Pernambuco, Brasil João Freire Filho, Universidade Federal do Rio de Janeiro, Brasil John DH Downing, University of Texas at Austin, Estados Unidos José Afonso da Silva Junior, Universidade Federal de Pernambuco, Brasil
José Carlos Rodrigues, Pontifícia Universidade Católica do Rio de Janeiro, Brasil José Luiz Aidar Prado, Pontifícia Universidade Católica de São Paulo, Brasil José Luiz Warren Jardim Gomes Braga, Universidade do Vale do Rio dos Sinos, Brasil Juremir Machado da Silva, Pontifícia Universidade Católica do Rio Grande do Sul, Brasil Laan Mendes Barros, Universidade Metodista de São Paulo, Brasil Lance Strate, Fordham University, USA, Estados Unidos Lorraine Leu, University of Bristol, Grã-Bretanha Lucia Leão, Pontifícia Universidade Católica de São Paulo, Brasil Malena Segura Contrera, Universidade Paulista, Brasil Márcio de Vasconcellos Serelle, Pontifícia Universidade Católica de Minas Gerais, Brasil Maria Aparecida Baccega, Universidade de São Paulo e Escola Superior de Propaganda e Marketing, Brasil Maria das Graças Pinto Coelho, Universidade Federal do Rio Grande do Norte, Brasil Maria Immacolata Vassallo de Lopes, Universidade de São Paulo, Brasil Maria Luiza Martins de Mendonça, Universidade Federal de Goiás, Brasil Mauro de Souza Ventura, Universidade Estadual Paulista, Brasil Mauro Pereira Porto, Tulane University, Estados Unidos Mirna Feitoza Pereira, Universidade Federal do Amazonas, Brasil Nilda Aparecida Jacks, Universidade Federal do Rio Grande do Sul, Brasil Paulo Roberto Gibaldi Vaz, Universidade Federal do Rio de Janeiro, Brasil Potiguara Mendes Silveira Jr, Universidade Federal de Juiz de Fora, Brasil Renato Cordeiro Gomes, Pontifícia Universidade Católica do Rio de Janeiro, Brasil Robert K Logan, University of Toronto, Canadá

Ronaldo George Helal, Universidade do Estado do Rio de Janeiro, Brasil Rose Melo Rocha, Escola Superior de Propaganda e Marketing, Brasil Rossana Reguillo, Instituto de Estudos Superiores do Ocidente, Mexico Rousiley Celi Moreira Maia, Universidade Federal de Minas Gerais, Brasil Sebastião Carlos de Morais Squirra, Universidade Metodista de São Paulo, Brasil Sebastião Guilherme Albano da Costa, Universidade Federal do Rio Grande do Norte, Brasil

Simone Maria Andrade Pereira de Sá, Universidade Federal Fluminense, Brasil Tiago Quiroga Fausto Neto, Universidade de Brasília, Brasil

Suzete Venturelli, Universidade de Brasilia, Brasil Valério Cruz Brittos, Universidade do Vale do Rio dos Sinos, Brasil Valerio Fuenzalida Fernández, Puc-Chile, Chile Veneza Mayora Ronsini, Universidade Federal de Santa Maria, Brasil Vera Regina Veiga França, Universidade Federal de Minas Gerais, Brasil

\section{COMISSÃO EDITORIAL}

Adriana Braga I Pontifícia Universidade Católica do Rio de Janeiro, Brasil

Felipe Costa Trotta I Universidade Federal Fluminense, Brasil

CONSULTORES AD HOC

Bruno Campanella, Universidade Federal Fluminense, Brasil

Gisela Grangeiro da Silva Castro, Escola Superior de Propaganda e Marketing, Brasi José Carlos Ribeiro, Universidade Federal da Bahia, Brasil

Luciana Panke, Universidade Federal do Paraná, Brasil

Micael Herschmann, Universidade Federal do Rio de Janeiro, Brasil

Tânia Márcia Cezar Hoff, Escola Superior de Propaganda e Marketing, Brasil

Virginia da Silveira Fonseca, Universidade Federal do Rio Grande do Sul, Brasil

EDIÇÃO DE TEXTO E RESUMOS I Susane Barros

SECRETÁRIA EXECUTIVA I Juliana Depiné

EDITORAÇÃo ELETRÔNICA I Roka Estúdio
COMPós I www.compos.org.br

Associação Nacional dos Programas de Pós-Graduação em Comunicação

Presidente

Julio Pinto

Pontifícia Universidade Católica de Minas Gerais, Brasil

juliopinto@pucminas.br

Vice-presidente

Itania Maria Mota Gomes

Universidade Federal da Bahia, Brasil

itania@ufba.br

Secretária-Geral

Inês Vitorino

Universidade Federal do Ceará, Brasil

inesvict@gmail.com 